\title{
Lactic acid production from paper sludge by SSF with thermotolerant Rhizopus sp.
}

\author{
Maki Takano and Kazuhiro Hoshino*
}

\begin{abstract}
Background: Rhizopus fungi is suitable for the production of lactic acid, which is the backbone material of polylactic acid used as green plastic from lignocellulosic biomass, since it can grow and ferment in simple medium with various carbon sources such as starch and cellulose. Although paper sludge (PS) contains a lot of cellulosic fibers and in general was incinerated for volume reduction and heat recovery, other efficient utilizations have hardly been developed. In effective production of lactic acid from PS, the research of the extraction of cellulosic fiber from raw PS to obtain effectively fermentable sugars by cellulase and the selection of lactic acid microorganism are necessary. In this study, the PS pretreatment method with $\mathrm{NaOH}$ and $\mathrm{HCl}$ and the optimization of cellulase reagent were achieved, and also a desirable thermotolerant Rhizopus was selected. Finally, the production of lactic acid from the treated PS at $40^{\circ} \mathrm{C}$ by simultaneous saccharification and fermentation (SSF) with the strain and an optimized cellulase cocktail was investigated.
\end{abstract}

Results: Rhizopus oryzae NBRC 5384 was selected for thermotolerant lactic acid production from Rhizopus library because of its heat tolerance up to $40^{\circ} \mathrm{C}$ and high lactic acid production of $80 \mathrm{~g} / \mathrm{L}$. The strain can ferment to lactic acid from hexose, pentose, sugar alcohol, disaccharide and starch. The soaking of raw PS in $\mathrm{NaOH}$ and $\mathrm{HCl}$ was able to reduce effectively inorganic materials and other reagents for repulping, and the content of Al and Ca per PS dry matter was mainly decreased from 32.9 and 30.8 to 14.1 and $1.66 \%$, respectively. SSF of the treated PS of $50 \mathrm{~g} / \mathrm{L}$ with optimized cellulase cocktail and 5384 at $40{ }^{\circ} \mathrm{C}$ resulted in lactic acid production of $9.33 \mathrm{~g} / \mathrm{L}$ for $96 \mathrm{~h}$.

Conclusion: The thermotolerant Rhizopus fungus was found based on its high performance in lactic acid production at high temperature from not only glucose, but also other various carbon sources including polysaccharides and the secretion of amylases and cellulases. The treatment of raw PS by $\mathrm{NaOH}$ and subsequent $\mathrm{HCl}$ was able to remove a large amount of inorganic materials with decrease of hydrophobicity. In SSF of the treated PS with the strain and the optimized cellulase cocktail, lactic acid was able to be produced. However, the increase of initial PS concentration in SSF led to the decrease of the yield with ethanol production, because of limited aeration due to increase of density. An appropriate oxygen supply to the strain is necessary to improve lactic acid production.

Keywords: Lactic acid, Paper sludge, Thermotolerant, Rhizopus oryzae, SSF

\section{Background}

Petrochemical production has caused worries amid concern about depletion of fossil fuel. Additionally, disposal treatment of a lot of the waste plastic is also a major consideration. As one of the sustainable green plastic materials, polylactic acid synthesized from lactic acid has been used increasingly as an alternative to petrochemical

\footnotetext{
*Correspondence: khoshino@eng.u-toyama.ac.jp Graduate School of Science and Engineering, University of Toyama, 3190 Gofuku, Toyama 930-8555, Japan
}

plastics. It can be discarded into the soil because of its biodegradability; the matter may be decomposed by microorganisms and used as carbon sources for plants and microorganisms. Lactic acid and its derivatives are also important chemicals that have many applications in food, chemical and pharmaceutical products (Passos et al. 1994; Datta et al. 1995; Lunt 1998; Grade et al. 2002). While it is produced by chemical synthesis, this manufacturing method results in a racemic mixture of $\mathrm{D}$ and L-lactic acids. As enantiopure lactic acid is required 
to produce polylactic acid which is stable structurally and does not contain impurities, lactic acid production by bioconversion has attracted attention because of its economical procedure compared with chemical synthesis. Moreover, the biological production method of lactic acid is valid because of the possibility of using lignocellulosic materials as feedstock.

Rhizopus fungi belonging to Zygomycota are well known microbes of enantiopure L-lactic acid from glucose and other carbon sources. The fungi are also able to ferment starch to lactic acid (Ping Huang et al. 2005; Yin et al. 1997; Zhou et al. 1999). Furthermore, several researches have been reported about the fungus, by which cellulolytic and xylanolytic enzymes were secreted (Bakir et al. 2001; Murashima et al. 2002). The saprophytic fungus has high potential for lactic acid production from various abundant cellulosic biomasses, such as agricultural (rice straw, wheat straw), forestry (wood) and industrial waste (old paper, paper sludge) (Lynd et al. 1991, 1999; Lynd et al. 2001; Wyman 2003; Gao et al. 2008; Marques et al. 2008; Hama et al. 2015). Rhizopus fungi can produce L-lactic acid from simple media with not only several monosaccharides, but also starch and lignocelluloses with lower production cost than that by other lactic acid bacteria though many kinds of microorganisms such as Lactobacillus, Lactococcus and Enterococcus (Woiciechowski et al. 1999; Thongchul and Yang 2003; Wang et al. 2010). Additionally, Rhizopus can produce three major end products of $\mathrm{L}$-lactic acid, fumaric acid and ethanol, unlike homofermentative lactic acid bacteria. These products are affected by culture condition, and sufficient aeration induces efficient lactic acid (Cui et al. 1998; Skory et al. 1998).

Paper sludge (PS) is a solid residue arising from paper manufacture and the generated amount is more than 3.5 million ton per year in Japan, according to statistic data on industrial waste from paper manufacturing by the Japan Paper Association. Since it is mainly incinerated to reduce the volume and regenerate thermal energy, the use of a lot of fossil fuel for the discard treatment has been viewed with suspicion, because PS has high moisture content up to $50 \%$ and incineration discharges a large amount of $\mathrm{CO}_{2}$. Also, the utilization of PS ash derived from the incineration is limited and is used as filling materials for cement, asphalt and rubber, or as a material for manufacturing cement (Ishimoto et al. 2000). Though a small part of PS is used as a soil conditioner and a fertilizer in agriculture, a large part of ash is disposed of in sanitary landfills (Henry 1991; Tripepi et al. 1996). Therefore, new technology of effective utilization of PS should be developed for not only the production of sustainable materials as alternative to petrochemicals, but also the reduction of paper waste. PS is a promising material as one of a lignocellulosic feedstock for lactic acid production from the content of a large amount of short cellulosic fibers already treated by delignification of paper making. While PS has already been transmuted to cellulosic fiber in the pulping process by digestion with alkali and steam, general pretreatment of lignocellulosic biomasses needs high energy to delignify and expose the cellulose fiber. However, the PS contains a large amount of paper filler materials, such as $\mathrm{CaCO}_{3}$, kaolin $\left(\mathrm{Al}_{2} \mathrm{Si}_{2} \mathrm{O}_{5}(\mathrm{OH})_{4}\right)$, talc $\left(\mathrm{Mg}_{3} \mathrm{Si}_{4} \mathrm{O}_{10}(\mathrm{OH})_{2}\right)$ and other inorganic materials, and it is possible to be an inhibitor of enzymatic reaction and metabolism of microorganism for the bioconversion of PS. The fillers and the other additives in PS envelop the cellulose fibers and obstruct the access of microbes and enzymes to the cellulose substrate (Nikolov et al. 2000). Cellulase hydrolysis is especially inhibited by $\mathrm{CaCO}_{3}$, because the $\mathrm{pH}$ of this reaction suspension ( $\mathrm{pH} 6-8)$ is relatively higher than the optimum pH of cellulases. (Kang et al. 2010). Although $\mathrm{CaCO}_{3}$ is essential for $\mathrm{pH}$ control for lactic acid production to suppress $\mathrm{pH}$ decrease by the acid, removal of ash in PS leads to effective hydrolysis of PS and lactic acid production. $\mathrm{CaCO}_{3}$ can be removed by acid dissolution or $\mathrm{CO}_{2}$ treatment (Kang et al. 2011).

In this study, lactic acid production by an appropriate Rhizopus fungus from PS that removed the inorganic materials was investigated using simultaneous saccharification and fermentation (SSF) method. In SSF, the enzymatic hydrolysis step of cellulose and the fermentative step by microorganisms are typically combined and the cultivation is operated on a one-batch system (Abe and Takagi 1991; Yanez et al. 2003). Unfortunately, appropriate temperatures for the enzymes and microbes are in general very different. As optimum temperature of cellulases are generally $40-60{ }^{\circ} \mathrm{C}$ and the growth temperature of the common lactic acid bacteria is around $30{ }^{\circ} \mathrm{C}$, SSF must be operated at the growth temperature which causes the cellulase activities to decrease. To achieve effective SSF, thermotolerant Rhizopus strain was selected. Several strains can grow and produce lactic acid up to $40{ }^{\circ} \mathrm{C}$ (Kitpreechavanich et al. 2008). Conversion of PS to lactic acid by SSF was studied with thermotolerant Bacillus; however, it was not able to secrete cellulases (Marques et al. 2008; Naresh and Zhiliang 2009). Since Rhizopus sp. is able to secrete cellulases and hemicellulases, SSF will be able to perform with addition of relatively low-dose cellulase economically. Therefore, the selection of thermotolerant Rhizopus strain, removal of $\mathrm{CaCO}_{3}$ from raw PS and lactic acid production from the treated PS by SSF with the strain and cellulase cocktail were investigated. 


\section{Methods}

\section{Materials}

To evaluate lactic acid production, 55 kinds of Rhizopus sp. was obtained from NBRC (NITE Biological Resource Center, Chiba, Japan). These strains were maintained on Difco ${ }^{\mathrm{TM}}$ potato dextrose agar (PDA) slants at $4{ }^{\circ} \mathrm{C}$.

The paper sludge (PS) used in this study was supplied from the final waste sludge discharge spout of deinked pulp manufacturing process in Chuetsu Pulp \& Paper Co., Ltd. (Toyama, Japan). The moisture content of PS was around $50 \%$ by squeezing of the filler-pressed machine. It was sealed in plastic Ziploc bags and stored at $-30{ }^{\circ} \mathrm{C}$ until experimental use. PS was analyzed after oven drying at $50{ }^{\circ} \mathrm{C}$ to constant weight. The PS components of cellulose, hemicellulose, lignin, acid-soluble lignin and ash were assayed by Klason lignin method (Lopez et al. 2010).

Cellulases in this study used 15 kinds of commercial reagents as follows: Meicelase (Meiji Seika Pharma, Japan), Cellulase T "Amano" 4, Cellulase A "Amano" 3, Pectinase G "Amano", Hemicellulase "Amano" 90(Amano Enzyme, Japan), Cellulase Y-NG, Cellulase "Onozuka" 3S, Cellulase "Onozuka" R-10 (Yakult Pharmaceutical Industry, Japan), Sumizyme AC, Sumizyme X, Sumizyme SNX (Shin-Nihon Kagakukogyo, Japan), Cellulase Trichoderma viride, Novozyme 188 (Sigma-Aldrich Co., St Louis, MO), Accellerase ${ }^{\circledR}$ (DuPont, DE, USA) and Vecelex (Godo-Shusei, Japan).

\section{Removal of inorganic materials from raw PS by alkali and acid solution}

Raw PS was suspended in $1 \mathrm{M} \mathrm{NaOH}$ solution with $200 \mathrm{~g} / \mathrm{L}$ consistency and soaked overnight. After the PS fiber was separated from the alkaline liquid, it was resuspended in appropriate $\mathrm{HCl}$ solution of the required concentration for neutralization of both residual $\mathrm{NaON}$ and $\mathrm{CaCO}_{3}$ contained in PS and soaked overnight. The PS was separated from the acid solution and thoroughly washed with water. The PS treated by $\mathrm{NaOH}$ and $\mathrm{HCl}$ was oven dried at $50{ }^{\circ} \mathrm{C}$, completely dried and then powdered finely in a mill.

Selection and determination of optimum cellulase cocktail The treated PS of $50 \mathrm{~g} / \mathrm{L}$ was hydrolyzed by each 15 kinds of commercial cellulase at the protein concentration of $1 \mathrm{~g} / \mathrm{L}$ in $100 \mathrm{~mL}$ bottles containing $25 \mathrm{~mL}$ acetic acid buffer ( $\mathrm{pH}$ 5.0). These were shaken in a rotary shaker at $120 \mathrm{rpm}$ at $40{ }^{\circ} \mathrm{C}$ for $48 \mathrm{~h}$ and then hydrolysates were separated by filtration (Filter paper No.131, Advantec Co., Tokyo, Japan) and analyzed by HPLC. The cellulase reagents that were able to produce a lot of fermentable sugar (glucose and xylose) from the PS were selected, and their blending ratio was determined by the design of experiment method using Design Expert 8 (Stat-Ease, Inc. MN).

\section{Cultivation of Rhizopus fungi}

Fungi were precultured on PDA plate at $40{ }^{\circ} \mathrm{C}$ until they covered the overall surface. The mycelia on a plate were milled using a blender (Milser LM-Plus, Osaka chemical Co., Osaka, Japan) in $100 \mathrm{~mL}$ saline per plate and it was used as inoculums. The composition of the culture medium was $120 \mathrm{~g} / \mathrm{L}$ glucose, $3 \mathrm{~g} / \mathrm{L}\left(\mathrm{NH}_{4}\right)_{2} \mathrm{SO}_{4}, 0.3 \mathrm{~g} / \mathrm{L}$ $\mathrm{KH}_{2} \mathrm{PO}_{4}, 0.25 \mathrm{~g} / \mathrm{L} \mathrm{MgSO}_{4} \cdot 7 \mathrm{H}_{2} \mathrm{O}, 0.04 \mathrm{~g} / \mathrm{L} \mathrm{ZnSO} \cdot \cdot 7 \mathrm{H}_{2} \mathrm{O}$, and $50 \mathrm{~g} / \mathrm{L} \mathrm{CaCO}_{3}$. All reagents used were purchased from Wako Pure Chemical Industries, Ltd (Osaka, Japan). The medium of $25 \mathrm{~mL}$ was put in a $100 \mathrm{ml}$ medium bottle and then sterilized at $121{ }^{\circ} \mathrm{C}$ for $15 \mathrm{~min}$. After getting cold, the cap of the medium bottle was exchanged with a silicone plug (Type C: Asone Co. Tokyo, Japan). Cultivation of fungi was started by inoculation of $1 \mathrm{~mL}$ hypha suspension into the medium and then incubated in a rotary shaker $(120 \mathrm{rpm})$ at $40{ }^{\circ} \mathrm{C}$. After the cultivation, $5 \mathrm{ml}$ of $5 \mathrm{M} \mathrm{HCl}$ was added to each bottle for dissolution of $\mathrm{CaCO}_{3}$, and the broth was separated by filtration. Residual sugar and lactic acid in the culture were analyzed by HPLC.

\section{Enzymatic hydrolysis and simultaneous saccharification and fermentation (SSF) of the treated PS}

For lactic acid production from treated PS, 50 or $100 \mathrm{~g} / \mathrm{L}$ of the treated PS was used as substrate instead of glucose. Medium components and the PS in $500 \mathrm{~mL}$ baffle flasks were sterilized at $121{ }^{\circ} \mathrm{C}$ for $15 \mathrm{~min}$. Enzymatic hydrolysis was started by the addition of filter-sterilized cellulase cocktail, which consisted of three enzyme reagents at a calculated rate and protein with a concentration of $3.5 \mathrm{~g}$ protein/L (containing endo- $\beta$-glucanase, endo- $\beta$ xylanase, cellobiohydrolase, $\beta$-glucosidase, $\beta$-xylosidase and FPase whose activities were 10.4, 30.4, 0.214, 2.44, 0.0429 and $0.473 \mathrm{U} / \mathrm{mL}$, respectively), into the medium and then shaking at $130 \mathrm{rpm}$ for $144 \mathrm{~h}$ at $40{ }^{\circ} \mathrm{C}$. SSF was started by the addition of $8 \mathrm{~mL}$ of homogenized mycelium suspension and the cellulase cocktail, and then they were cultured at the same condition of hydrolysis. Hydrolysates and broths sampled from cultures were analyzed by HPLC for determination of sugars and lactic acid.

\section{Analytical method}

In the case of Klason lignin method, glucose was measured by Glucose C II-test Wako (Wako Pure Chemical Industries, Ltd., Osaka, Japan) and total sugar was measured by the phenol-sulfuric acid method. Elemental composition in the ash of PS was determined by X-ray fluorescence analysis (XRF) using wave length-dispersive X-ray spectroscopy (PW2404, Spectris Co., Ltd., Tokyo, Japan). The amount of glucose, xylose, and lactic acid from each cultivation was determined by HPLC (LC10ADvp, Shimadzu Co., Kyoto, Japan) equipped with a 
refractive index detector (RID-10A, Shimadzu Co.) and ICSep WA-1 Wine Analysis column (Transgenomic, NE, USA) operated at $40{ }^{\circ} \mathrm{C}$ with $1.25 \mathrm{mM}$ sulfuric acid as mobile phase at flow rate of $0.6 \mathrm{~mL} / \mathrm{min}$.

\section{Result and discussion}

\section{Removal of inorganic materials from PS}

Since raw PS is the final residue of recycled paper manufacturing, PS containing many components with the exception of cellulose and hemicelluloses fibers such as $\mathrm{CaCO}_{3}$ from loading materials, reagents and surfactants by the deinking and the repulping. These materials have the possibility of becoming inhibitors of hydrolysis of enzymes and fermentation of microorganism, especially, a large amount of $\mathrm{CaCO}_{3}$ covering the cellulose fiber might obstruct the attack of enzymes and microbes. To remove these inhibitors for the effective hydrolysis of PS and subsequent fermentation, their removal process by dissolution with alkali and acid solution was investigated.

First, raw PS was soaked in $1 \mathrm{~N} \mathrm{HCl}$ solution to dissolve $\mathrm{CaCO}_{3}$ in PS. The treatment resulted in the decrease of the component ratio of inorganic materials from 41.9 to $28.7 \%$ with increase in the ratio of cellulose and other sugars of 14.0 and $8.4 \%$, respectively, as shown in Table 1. While partial inorganic materials were removed from raw PS by the $\mathrm{HCl}$ treatment, the treated PS became strong water-shedding fibers because of the exposure of the hydrophobic surface of the fiber by uncovering of $\mathrm{CaCO}_{3}$.

Next, raw PS was soaked in $1 \mathrm{~N} \mathrm{NaOH}$ before the $\mathrm{HCl}$ treatment in an effort to reduce the hydrophobicity with dissolution of reagents and surfactants used on repulping adsorbed on PS by the alkali solution. The $\mathrm{NaOH}-\mathrm{HCl}$ treatment resulted in the augmentation of hydrophilicity with removal of $24.5 \%$ inorganic materials and increase of cellulose and other sugar contents to 51.3 and $22.4 \%$,

Table 1 Components ratio in raw and each treated PS

\begin{tabular}{llll}
\hline Content (\%) & Raw & HCl & NaOH-HCl \\
\hline Cellulose & 22.4 & 36.3 & 51.3 \\
Other sugars & 10.1 & 18.6 & 22.4 \\
Inorganic materials & 41.9 & 28.7 & 17.4 \\
Others & 25.5 & 16.3 & 8.88 \\
\hline
\end{tabular}

respectively. The elemental components ratio in PS ash by X-ray fluorescence analysis is shown in Table 2 . The reduced inorganic materials were mainly $\mathrm{Ca}, \mathrm{Al}$, and $\mathrm{Fe}$ elements in PS and the decrease ratios were 29.1, 18.9, and $1.84 \%$, respectively. From these results, it was shown that the $\mathrm{NaOH}-\mathrm{HCl}$ treatment method was excellent for the disposal of $\mathrm{CaCO}_{3}$ from raw PS.

\section{Selection of thermotolerant lactic acid-producing strain}

To select the best strain that was able to grow at $40{ }^{\circ} \mathrm{C}$ and concurrently to produce effectively lactic acid among 55 species of Rhizopus library, they were first cultured at $40{ }^{\circ} \mathrm{C}$ on a PDA plate. Forty species in the library could well grow under the environment. Next, they were cultured in liquid medium under the aerobic condition at $40{ }^{\circ} \mathrm{C}$, and then the lactic acid produced for $144 \mathrm{~h}$ was determined. Figure 1 shows that lactic acid production by the fungi selected as the thermotolerant strain. It was recognized that 22 kinds of species were able to produce it. Since $R$. oryzae NBRC 5384, 5413 and 31,005 was produced more than $50 \mathrm{~g} / \mathrm{L}$ lactic acid from $120 \mathrm{~g} / \mathrm{L}$ glucose, three strains was re-cultured and the detailed investigation of the products was performed. As a result, three strains produced mainly lactic acid with a small amount of fumaric acid as shown in Table 3. Maximum lactic acid concentrations were produced were at about $66-74 \mathrm{~g} / \mathrm{L}$ for $120 \mathrm{~h}$. Though $R$. oryzae NBRC 31,005 strain was reported to preferentially produce fumaric acid $(47.8 \mathrm{~g} / \mathrm{L})$ with a small amount of lactic acid $(9.7 \mathrm{~g} / \mathrm{L})$ at $30{ }^{\circ} \mathrm{C}$ (Yin et al. 1997), it was able to produce conversely high lactic acid with fumaric acid of $0.22 \mathrm{~g} / \mathrm{L}$ at $40{ }^{\circ} \mathrm{C}$ in this study. Yet on thermotolerance, it is noteworthy that only $R$. oryzae NBRC 5384 was able to grow up to $50{ }^{\circ} \mathrm{C}$. Therefore, the $R$. oryzae NBRC 5384 strain was selected as a thermotolerant fungus for the production of lactic acid because of the highest heat tolerance.

\section{Lactic acid production by $R$. oryzae NBRC 5384 by difference of incubation temperatures}

$R$. oryzae NBRC 5384 was cultured with $120 \mathrm{~g} / \mathrm{L}$ glucose as a carbon source at $28,36,40$, and $42{ }^{\circ} \mathrm{C}$ for $144 \mathrm{~h}$ and the result is shown in Fig. 2. In all cultures, glucose was almost consumed and lactic acid was produced with the assimilation. It was found that the strain was also able to

Table 2 Elemental components ratio of ash in raw and treated PS

\begin{tabular}{|c|c|c|c|c|c|c|c|c|c|c|c|c|c|c|c|}
\hline & \multirow{2}{*}{$\begin{array}{l}\text { Ratio } \\
\text { of ash }\end{array}$} & \multicolumn{14}{|c|}{ Elemental components (\%) } \\
\hline & & Al & $\mathrm{Ca}$ & $\mathrm{Si}$ & Mg & $\mathrm{Fe}$ & $\mathrm{Na}$ & $S$ & $\mathbf{P}$ & $\mathrm{Ti}$ & $\mathrm{Cl}$ & $\mathrm{K}$ & $\mathrm{Mn}$ & $\mathrm{Zn}$ & $\mathrm{Cu}$ \\
\hline Raw & 1 & 32.9 & 30.8 & 16.4 & 5.77 & 3.55 & 3.24 & 2.95 & 1.99 & 0.643 & 0.490 & 0.426 & 0.412 & 0.244 & 0.114 \\
\hline Treated & 0.537 & 14.1 & 1.66 & 24.3 & 6.07 & 1.71 & 2.53 & 0.743 & 0.905 & 0.840 & 0.216 & 0.401 & 0.0759 & 0.0684 & 0.115 \\
\hline
\end{tabular}

${ }^{a}$ Based on the content of inorganic material (ash) in raw PS 


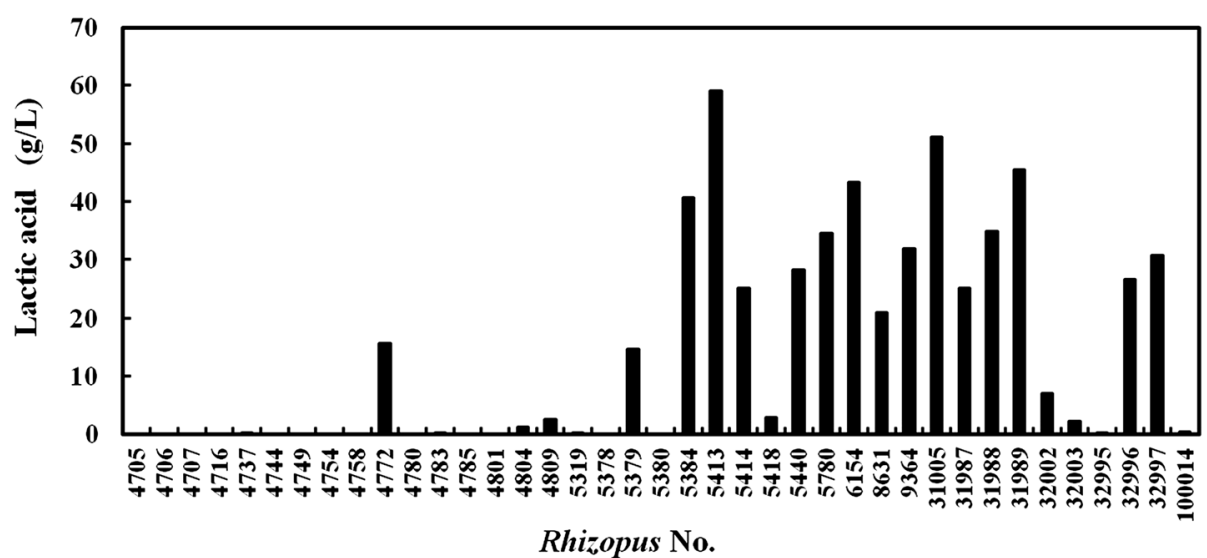

Fig. 1 Comparison of lactic acid production from glucose by various Rhizopus strains. Lactic acid concentration produced from $120 \mathrm{~g} / \mathrm{L}$ glucose by each Rhizopus strain cultivated for $144 \mathrm{~h}$ at $40^{\circ} \mathrm{C}$

Table 3 Comparison of lactic acid and fumaric acid produced by three strains of Rhizopus

\begin{tabular}{lll}
\hline Strain & $\begin{array}{l}\text { Lactic } \\
\text { acid (g/L) }\end{array}$ & $\begin{array}{l}\text { Fumaric } \\
\text { acid (g/L) }\end{array}$ \\
\hline NBRC 5384 & 69.8 & 0.164 \\
NBRC 5413 & 65.9 & 0.0581 \\
NBRC 31005 & 73.9 & 0.167 \\
\hline
\end{tabular}

All cultures were carried out for $120 \mathrm{~h}$ at $40^{\circ} \mathrm{C}$

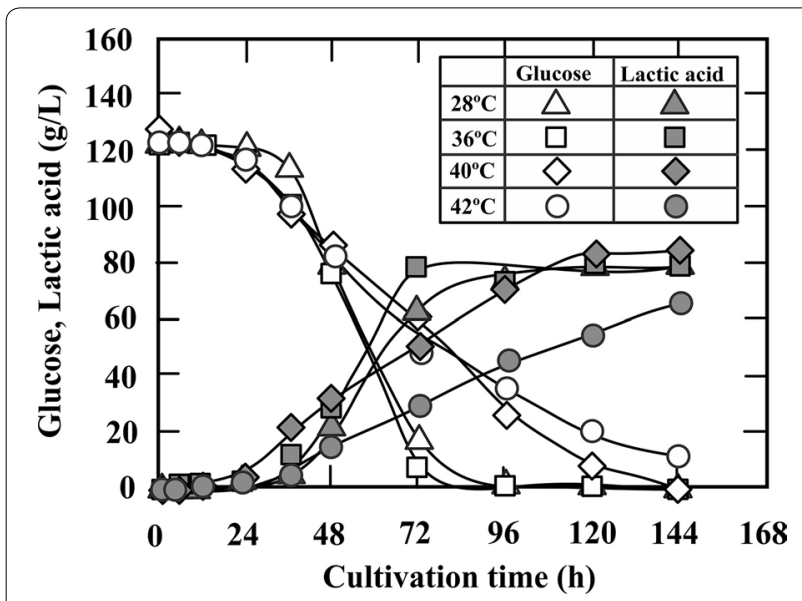

Fig. 2 Effect of temperature on lactic acid production from glucose by $R$. oryzae NBRC 5384. Cultivation was performed at the initial glucose concentration of $120 \mathrm{~g} / \mathrm{L}$ at the temperature of $28,36,40$, and $42{ }^{\circ} \mathrm{C}$

produce lactic acid at $42{ }^{\circ} \mathrm{C}$. Lactic acid was produced up to about $80 \mathrm{~g} / \mathrm{L}$ in $120 \mathrm{~h}$ except for the culture at $42{ }^{\circ} \mathrm{C}$, although the rates were different at each temperature. The rates of lactic acid production increased with temperature rising until $36{ }^{\circ} \mathrm{C}$ and decreased at the temperature up to $42{ }^{\circ} \mathrm{C}$. The productivities were $0.894(72 \mathrm{~h})$,
$1.11(72 \mathrm{~h}), 0.692(120 \mathrm{~h})$ and $0.462 \mathrm{~g} / \mathrm{L} / \mathrm{h}(144 \mathrm{~h})$, respectively. From these results, it is found that 5384 strain is applicable to lactic acid production at high temperature of about $40^{\circ} \mathrm{C}$; then it was decided that the following cultures is mainly carried out at $40{ }^{\circ} \mathrm{C}$ to maintain stable and effective fermentation.

\section{Characterization of lactic acid production from several carbohydrates by $R$. oryzae NBRC 5384}

Lactic acid productions by $R$. oryzae NBRC 5384 from 15 kinds of carbohydrates (hexoses, pentoses, sugar alcohol, disaccharides and polysaccharides) as carbon source were carried out at $40{ }^{\circ} \mathrm{C}$ to characterize the lactic acid fermentation ability of the strain. The culture was performed with $50 \mathrm{~g} / \mathrm{L}$ of each carbon source for $120 \mathrm{~h}$ and the produced lactic acid and the yields are shown in Table 4 . The strain was able to convert efficiently hexoses such as glucose, galactose, mannose and fructose to lactic acid, and in these cultures the yields of lactic acid based on the initial carbon sources were about 0.62-0.65. The strain was also able to ferment to lactic acid from not only hexoses, but also slightly from pentoses such as xylose and arabinose. Moreover, although common lactic acid microorganism cannot use sugar alcohols for lactic acid production, the strain was able to ferment sorbitol slightly. Though maltose and cellobiose were converted to lactic acid by the stain, lactose was not fermented. These results means that the strain could produce $\alpha$ and $\beta$-glucosidases though $\beta$-fructofuranosidase could not be produced. Since direct fermentation of soluble starch to lactic acid was able to be carried out, the secretion of $\alpha$-amylase and/or glucoamylase by the strain was also suggested. $\alpha$-cellulose was not able to ferment under the culture condition. It is thought that the hydrolysis of $\alpha$-Cellulose by cellulases such as endo- $\beta$-gluconase, 
Table 4 Ability of $R$. oryzae NBRC 5384 to produce lactic acid using various carbon sources

\begin{tabular}{lll}
\hline & Lactic acid (g/L) & Yield $(\mathbf{g} / \mathbf{g})^{\mathbf{a}}$ \\
\hline Glucose & 34.2 & 0.648 \\
Galactose & 32.7 & 0.654 \\
Mannose & 31.0 & 0.620 \\
Fructose & 32.9 & 0.658 \\
Xylose & 5.23 & 0.105 \\
Arabinose & 0.13 & 0.0026 \\
Sucrose & 0.243 & 0.00486 \\
Maltose & 36.5 & 0.730 \\
Cellobiose & 6.55 & 0.131 \\
Lactose & 0 & 0 \\
Glycerol & 0 & 0 \\
Sorbitol & 8.31 & 0.166 \\
Mannitol & 0 & 0 \\
Soluble starch & 6.80 & 0.136 \\
a-Cellulose & 0 & 0 \\
\hline
\end{tabular}

All cultures were carried out for $120 \mathrm{~h}$ at $40^{\circ} \mathrm{C}$

a Based on the initial concentration of each sugar (50 g/L)

cellobiohydrolase, $\beta$-glucosidase et al. was not enough for the lactic acid production although the strain was secreted the slightly several cellulases (data is not shown). To produce lactic acid from cellulosic biomass with the fungus, it is necessary to add cellulases into the culture. Especially, it is necessary to execute an SSF combining of cellulase and thermotolerant fungus for the lactic acid production from treated PS, including short cellulose fiber that has a stronger structure than $\alpha$-cellulose by SSF.

\section{Lactic acid production from PS treated by SSF with thermotolerant fungus}

Moreover, the hydrolysis rate of the cellulosic fiber might be greatly controlled by the compounding ratio of these enzymatic activities depending on the type of substrate. Although the commercial cellulase reagent, which has various cellulase activities, was optimized to hydrolyze effectively targeting cellulosic materials, the cellulase reagent for hydrolysis of PS is not available and effective hydrolysis is difficult by only a commercial reagent. Therefore, the blending of several commercial reagents is a promising strategy to obtain fermentable sugars from treated PS. First, the hydrolysis reaction of treated PS by 15 kinds of commercial reagents was carried out for selection at each concentration of $1 \mathrm{~g}$ protein/L and $50 \mathrm{~g}$ PS/L for $24 \mathrm{~h}$ to compare the initial hydrolysis rates. Among all the reagents, Cellulase Onozuka 3S (O) and Accellelase (A) were produced from most fermentable sugars (total amount of glucose and xylose) from the PS. Next, the optimization of commercial cellulase reagents was performed by Design of Experiment (DOE) method with Design Expert 8.0. for effective hydrolysis of treated PS. The ratio calculated using DOE was $\mathrm{O}: \mathrm{A}=0.157: 0.843$. Additionally, $0.5 \mathrm{~g}$ protein/L Pectinase $G(P)$ was used as a supplement of $\beta$-xylosidase activity for xylose production from hemicellulose in treated PS, because the activities of two selected reagents were weak. From these results, a desirable cellulase cocktail was constructed at the ratio of $\mathrm{O}: \mathrm{A}: \mathrm{P}=0.47: 2.53: 0.50$ (total concentration was 3.5 g-protein/L).

For confirmation of hydrolysis ability against treated PS of the cocktail, substantiative hydrolysis was performed with the cellulose cocktail at 28 and $40{ }^{\circ} \mathrm{C}$. Figure 3 shows the fermentable sugars (glucose and xylose) produced from $100 \mathrm{~g} / \mathrm{L}$ treated PS (4.73 FPU/g-PS) at 28 and $40{ }^{\circ} \mathrm{C}$. The hydrolysis rate was increased with rising temperature, the maximum concentrations of glucose were 32.1 and $38.3 \mathrm{~g} / \mathrm{L}$ for $72 \mathrm{~h}$, respectively, and the glucose yield at $40{ }^{\circ} \mathrm{C}$ was 0.747 based on cellulose content in the treated PS. However, xylose production was only increased slightly by higher temperature. Though the existence of $\mathrm{CaCO}_{3}$ in the reaction medium was caused at $\mathrm{pH} 6-8$ and it induced inhibition of cellulase activity, hydrolysis efficiency of cellulose was achieved up to $70 \%$ and improved obviously with rising temperature. This can lead to increase of fermentation efficiency by SSF.

Figure 4 shows the lactic acid production from PS treated by SSF at $40{ }^{\circ} \mathrm{C}$, combining a thermotolerant strain with the cellulase cocktail. Glucose and xylose were produced rapidly at the initiation of culture and then consumed until the cultivation time of $24 \mathrm{~h}$, and subsequently not detected. At $24 \mathrm{~h}$, lactic acid began to

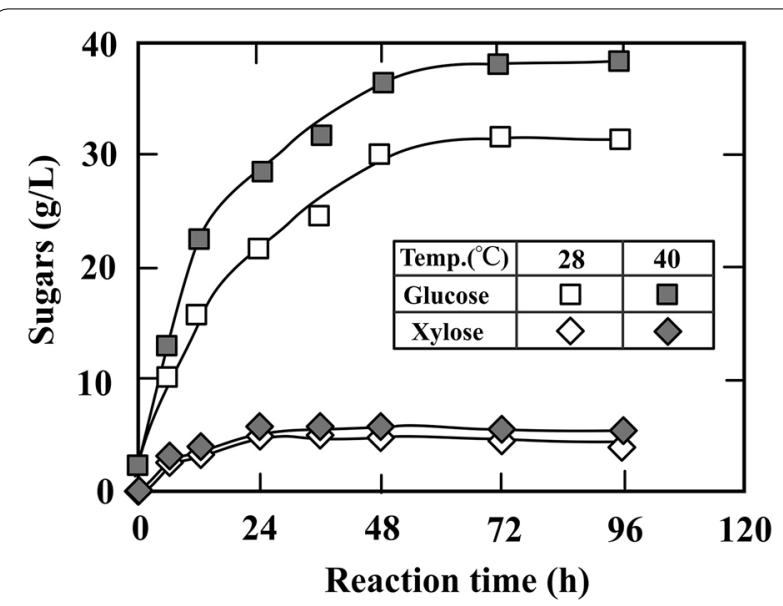

Fig. 3 Glucose and xylose production from the PS treated with optimum cellulase cocktail. Enzymatic hydrolysis of the PS at the initial concentration was $100 \mathrm{~g} / \mathrm{L}$ with cellulase cocktail containing $3.5 \mathrm{~g}$-protein $/ \mathrm{L}$ and the reaction was performed at 28 and $40^{\circ} \mathrm{C}$ 


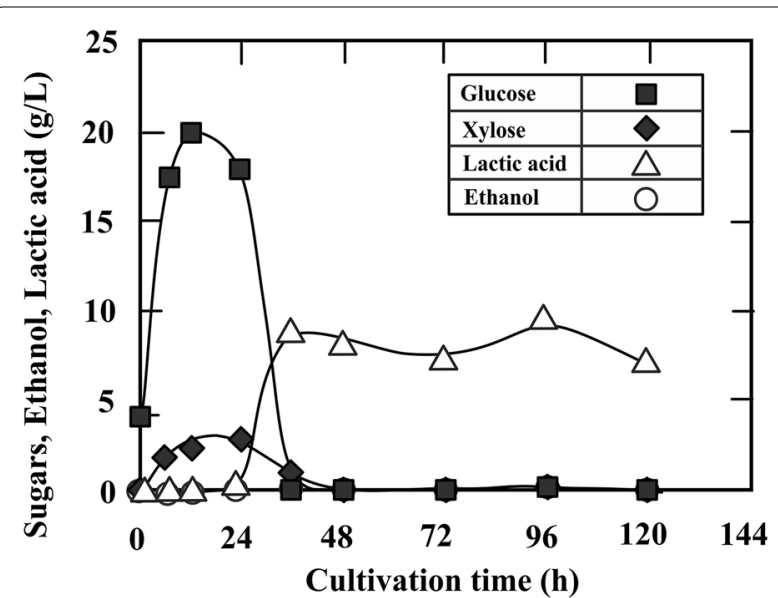

Fig. 4 Lactic acid production by SSF of the treated PS with 5384 strain and cellulase cocktail. The initial concentration of the PS was $50 \mathrm{~g} / \mathrm{L}$ and the cultivation was performed at $40^{\circ} \mathrm{C}$ with cellulase cocktail containing $9.46 \mathrm{FPU} / \mathrm{g}-\mathrm{PS}$ produce suddenly and its concentration reached $9.33 \mathrm{~g} / \mathrm{L}$ in $96 \mathrm{~h}$. The yield of lactic acid based on the sugar produced from the treated PS was 0.475 . The reason for the delay in the beginning of lactic acid production is that in the initial stage of culture, the fungus was grew using the energy obtained by sugar metabolism under aerobic condition and then the metabolism shifted to the lactic acid production side by accumulating the intracellular energy unlike in the case of the mechanism of a general lactic acid bacteria under anaerobic condition.

Meanwhile, in this SSF, neither ethanol nor fumaric acid, which were common by-products of lactic acid fermentation by Rhizopus sp., was detected. Although lactic acid was produced from PS treated by the SSF, its productivity of $0.244 \mathrm{~g} / \mathrm{L} / \mathrm{h}$ was less than that of the culture in the glucose substrate $(0.667 \mathrm{~g} / \mathrm{L} / \mathrm{h})$. Therefore, improvement of the lactic acid production by increasing the substrate concentration was attempted. Figure 5 shows the SSF treated with $100 \mathrm{~g} / \mathrm{L}$ PS at $40{ }^{\circ} \mathrm{C}$. During culture, lactic acid and ethanol were simultaneously produced from $24 \mathrm{~h}$ and then lactic acid $(7.56 \mathrm{~g} / \mathrm{L}$, at $48 \mathrm{~h}$ ) and ethanol $(5.25 \mathrm{~g} / \mathrm{L}$, at $36 \mathrm{~h})$ reached the maximum values. The yield of lactic acid at that point was 0.272 that was less than that with $50 \mathrm{~g} / \mathrm{L}$ treated PS. The lower yield is attributed to decrease of mass transfer in culture and fluidity by the increase of initial substrate concentration, because the treated PS was mainly composed of short light fibers. Moreover, judging by the fact that ethanol was produced at an initial culture, the environment in culture might induce suffocation through the SSF. That is, lactic acid production by the 5384 strain requires abundant oxygen and the depletion leads to shift to a pathway from pyruvate to ethanol production and not to lactic

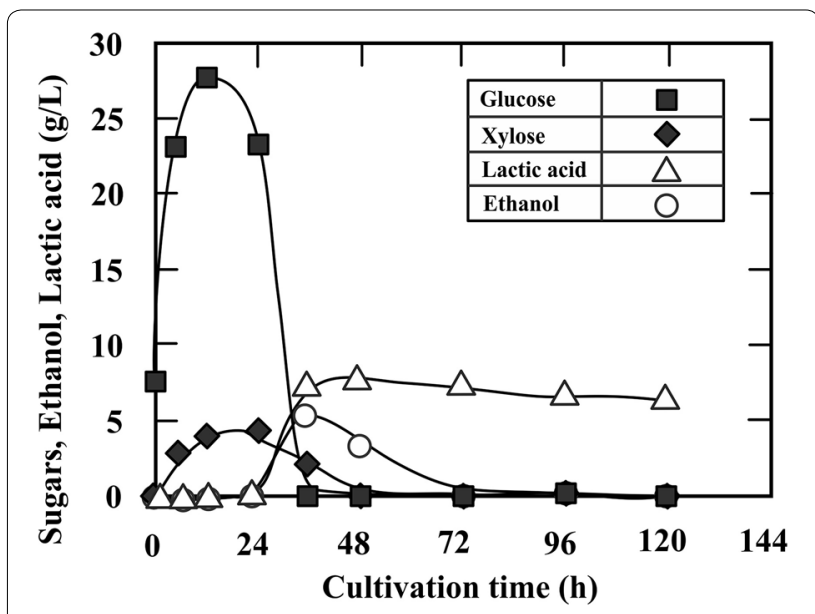

Fig. 5 Lactic acid production by SSF of the treated PS with 5384 strain and cellulase cocktail. The initial concentration of the PS was $100 \mathrm{~g} / \mathrm{L}$ and the cultivation was performed at $40^{\circ} \mathrm{C}$ with cellulase cocktail containing $4.73 \mathrm{FPU} / \mathrm{g}$-PS

acid production. From these results, at the start of SSF, a large amount of cell which accumulates enough energy intracellularly will produce lactic acid immediately, and the improvement of suffocation may be able to improve the delayed lactic acid. Compared to other researches on lactic acid production from several feedstocks, the yields and the productivities were low in this research on PS. For example, SSF of starch such as cassava, rice bran and wheat by Lactobacillus sp. resulted in the yields of $0.66,0.28$ and 0.89 and the productivities of $0.41,0.78$ and $1.74 \mathrm{~g} / \mathrm{L} / \mathrm{h}$, respectively (Chookietwattana 2014; Tanaka et al. 2006; Hetényi et al. 2011). In other researches of lactic acid from alfalfa fiber and cassava bagasse by the same species, the yields were 0.35 and 0.96 and the productivities were 0.75 and $1.40 \mathrm{~g} / \mathrm{L} / \mathrm{h}$, respectively (Sreenath et al. 2001; John et al. 2006). While these feedstocks are pure materials obtained from agriculture, PS used in this study is industrial waste and contains a lot of harmful components such as inorganic materials and various reagents for repulping, which inhibit hydrolases and microorganism. Since $\mathrm{pH}$ in culture is rendered faintly alkaline with $\mathrm{CaCO}_{3}$ which is the loading material for pulping and suppressor for $\mathrm{pH}$ decrease by the lactic acid produced, the activities of cellulases that have optimum $\mathrm{pH}$ at mild acid were depressed and the production of fermentable sugars was limited. Then lactic acid production by the fungus was delayed. Furthermore, the aeration of culture is important for enhancement of lactic acid production, because the 5384 strain used in this study responds sensitively against dissolved oxygen and switches ethanol production to lactic acid production by adequate oxygen supply. To improve the yield and 
productivity, investigation of the PS treatment method and cultivation condition should be carried out in detail. If the SSF process is accomplished with high efficiency, as the PS is a complex material and difficult to ferment than the other general cellulosic biomasses, it must be able to apply to other biomasses.

On the bioconversion from lignocellulosic biomass, which is applied not only to lactic acid but also to the other fermentation products, SSF is a more valid process than separate hydrolysis and fermentation (SHF) because the process can be carried out in one tank batch, though higher yields of fermentation products are achieved by SHF than SSF since it is possible to start high initial fermentable-sugars by the concentration of the hydrolysate (Hetényi et al. 2011). The reason why SSF progressed the production of lactic acid effectively is that it can avoid product inhibition against hydrolases by fermentable sugars, as the lactic acid fermentation microorganisms consume sugars formed by hydrolases at once. Although the SSF is commonly adopted for fermentation, it has a problem about difference of appropriate temperatures between cellulases and fermenting-microorganisms, and therefore the process is in general forced to execute at the low temperature agreed with an optimum temperature for fermenting microbes despite cellulases cannot keep maximum potential. To overcome the temperature gap, the application of thermotolerant fermenting-microorganisms for high-temperature SSF is effectual. It will be able to achieve the production of a large amount of fermentable sugars immediately by high cellulase activity and the subsequent fermentation. Enhancement of cellulases activity by increasing the temperature can lead to a reduction of cellulase usage in SSF and therefore the reduction in production cost will be accomplished. Moreover, though for low-temperature SSF the biomass has to be sterilized, since lignocellulosic biomasses includes a large amount of environmental microbes such as bacteria and fungi, the high-temperature SSF has the advantage that the contamination from biomass can be avoided easily. Therefore, there are many possibilities for the use of thermotolerant zymogenic microorganisms as biocatalyst for bioconversion of lignocellulosic feedstock to fermentation products.

\section{Conclusion}

With the slow depletion of fossil resource such as crude petroleum, the utilization of untapped natural resources has been received worldwide attention. The economical production of green plastic from lignocellulosic materials by bioconversion has recently been of interest in terms of carbon-neutral. Polylactic acid is one of the green plastic and lactic acid that is a raw material widely used in the field of food, chemical and pharmaceuticals, etc. In this research, paper sludge (PS) excreted as a waste product from the paper-making plant was focused on as an unused cellulosic material, because in the circumstances the treatment is in general carried out by incineration with a large amount of fossil fuel and therefore carbon dioxide has been generated. In addition, the PS ash is industrial waste and stable supply is more possible all the year round.

The production of lactic acid from PS containing a great amount of cellulose material was investigated using simultaneous saccharification and fermentation (SSF) with a new-found thermotolerant Rhizopus fungus and optimized cellulase cocktail. The screening of the fungus that can not only grow, but also ferment glucose to lactic acid at $40{ }^{\circ} \mathrm{C}$ was performed among the Rhizopus library in our laboratory, and some fungi belonging to $R$. oryzae and $R$. microsporus were able to grow at more than $40{ }^{\circ} \mathrm{C}$ and produce lactic acid. Taking the tolerance to high temperature and the ability of lactic acid production into consideration, $R$. oryzae NBRC 5384 was selected as the fungus for the production of lactic acid by SSF of PS. The strain was able to produce lactic acid from glucose in high yield under the aerobic condition at $40{ }^{\circ} \mathrm{C}$. Moreover, various sugars such as hexose, pentose, disaccharide and starch were directly bioconverted to lactic acid by the fungus. These results suggested that the strain can secrete $\alpha$ - and $\beta$-glucosidases, $\alpha$-amylase and glucoamylase.

Since in common SSF, the hydrolysis process was a rate-limiting step, and the improvement of its hydrolysis rate was the most important task for the effective production of lactic acid. To remove the unnecessary inclusion such as inorganic materials and deinked reagents used for paper manufacturing which inhibit cellulases activity and/or fermentation by thermotolerant fungus, the pretreatment of raw PS was investigated. PS treatment of soaking in $\mathrm{NaOH}$ and subsequently $\mathrm{HCl}$ was very efficient in the exposure of cellulosic fiber from PS, though its hydrophilicity was increased. $\mathrm{Ca}$ from $\mathrm{CaCO}_{3}$ in the loading material and $\mathrm{Al}$ from $\mathrm{Al}_{2} \mathrm{Si}_{2} \mathrm{O}_{5}(\mathrm{OH})_{4}$ in kaolin were mainly decreased by the treatment. Removal of inhibitors against enzymatic reaction by cellulases and fermentation by the fungus were efficiently executed with recovery of the cellulosic fiber in PS.

The optimization of cellulase reagent was performed by the DOE method based on the total amount of fermentable sugar (glucose plus xylose) produced from the treated PS with 14 kinds of commercial cellulase reagents. The total amount of fermentable-sugars formed from the treated PS by using the cocktail at $40{ }^{\circ} \mathrm{C}$ was vastly superior to that at $28^{\circ} \mathrm{C}$. Moreover, lactic acid was able to be produced by SSF of the treated PS at $40{ }^{\circ} \mathrm{C}$ with a new thermotolerant fungus, Rhizopus oryzae NBRC 5483, combined with the desirable cellulase cocktail. In the culture condition with high substrate concentration, the stagnation of oxygen 
supply to the strain might be caused the change of metabolic pathway. In particular, limitation of oxygen supply led to not only lactic acid, but also ethanol production.

As it now stands, although the amount of lactic acid produced from the treated PS by the SSF at $40{ }^{\circ} \mathrm{C}$ was low and the bioconversion has a problem relating to oxygen supply, the SSF might be one of promising methods for the utilization of PS as an unused cellulosic waste without $\mathrm{CO}_{2}$ emission, pushing ahead with the research as quickly as possible. The SSF process from PS will be able to achieve the production of various biomaterials such as not only lactic acid, but also other organic acids or ethanol in the near future.

\section{Authors' contributions}

TM carried out all PS treatments, enzymatic reactions, cultivations and analyses. TM has been involved in drafting the manuscript. HK has been involved in revising it critically for important intellectual content. HK has given final approval of the version to be published. Both authors read and approved the final manuscript.

\section{Acknowledgements}

This research was supported by A-STEP program (Industrial needs response type) of the Japan Science and Technology Agency (JST).

This study was presented at 12th Asian Congress on Biotechnology (ACB2015). Topic: Bioenergy and Biorefinery.

\section{Competing interests}

The authors declare that they have no competing interests.

Received: 4 January 2016 Accepted: 23 May 2016

Published online: 02 June 2016

\section{References}

Abe S, Takagi M (1991) Simultaneous saccharification and fermentation of cellulose to lactic-acid. Biotechnol Bioeng 37:93-96

Bakir U, Yavascaoglu S, Guvenc F, Etsayin A (2001) An endo- $\beta$-1,4-xylanase from Rhizopus oryzae: production, partial purification and biochemical characterization. Enzyme Microb Technol 29:328-334

Chookietwattana K (2014) Lactic acid production from simultaneous saccharification and fermentation of cassava starch by Lactobacillus plantarum MSUL 903. APCBEE Proc 8:156-160

Cui YQ, van der Lans RGJM, Luyben KCAM (1998) Effects of dissolved oxygen tension and mechanical forces on fungal morphology in submerged fermentation. Biotechnol Bioeng 57:409-419

Datta R, Tsai SP, Bonsignore P, Moon SH, Frank JR (1995) Technological and economic-potential of poly(lactic acid) and lactic-acid derivatives. FEMS Microbiol Rev 16:221-231

Gao L, Yang H, Wang X, Huang Z, Ishii M, Igarashi Y, Cui Z (2008) Rice straw fermentation using lactic acid bacteria. Bioresour Technol 99:2742-2748

Grade A, Jonsson G, Schmidt AS, Ahring BK (2002) Lactic acid production from wheat straw hemicellulose hydrolysate by Lactobacillus pentosus and Lactobacillus brevis. Bioresour Technol 81:217-223

Hama S, Mizuno S, Kihara M, Tanaka T, Ogino C, Noda H, Kondo A (2015) Production of D-lactic acid from hard wood pulp by mechanical milling followed by simultaneous saccharification and fermentation using metabolically engineered Lactobacillus plantarum. Bioresour Technol 187:167-172

Henry CL (1991) Nitrogen dynamics of pulp and paper sludge amendment to forest soils. Water Sci Technol 24:417-425

Hetényi K, Németh Á, Sevella B (2011) Investigation and modeling of lactic acid fermentation on wheat starch via SSF, CHF and SHF technology. Per Pol Chem Eng 55:11-16
Ishimoto H, Origuchi T, Yasuda H (2000) Use of papermaking sludge as new material. J Mater Civ Eng 12:310-313

John RP, Nampoothiri KM, Pandey A (2006) Simultaneous saccharification and fementation of cassava bagasse for $\mathrm{L}-(+)$-lactic acid production using Lactobacilli. Appl Biochem Biotechnol 134:263-272

Kang L, Wang W, Lee YY (2010) Bioconversion of kraft paper mill sludges to ethanol by SSF and SSCF. Appl Biochem Biotechnol 161:53-66

Kang L, Wang W, Pallapolu VR, Lee YY (2011) Enhanced ethanol production from de-ashed paper sludge by simultaneous saccharification and fermentation and simultaneous saccharification and co-fermentation. BioResour 6(4):3791-3808

Kitpreechavanich V, Maneeboon T, Kayano Y, Sakai K (2008) Comparative Characterization of L-lactic acid-producing thermotlerant Rhizopus fungi. J Biosci Bioeng 106:541-546

Lopez M, Huerta-Pujol O, Martinez-Farre FX, Soliva M (2010) Approachng compost stability from Klason lignin modified method: chemical stability degree for $\mathrm{OM}$ and $\mathrm{N}$ quality assessment. Recour Conserv Recy 55:171-181

Lunt J (1998) Large-scale production, properties and commercial applications of polylactic acid polymers. Polym Degrad Stabil 59:145-152

Lynd LR, Cushman JH, Nichols RJ, Wyman CE (1991) Fuel ethanol from cellulosic biomass. Science 251:1318-1323

Lynd LR, Wyman CE, Gerngross TU (1999) Biocommodity engineering. Biotechnol Prog 15:777-793

Lynd LR, Lyford C, South CR, van Walsum GP, Levenson K (2001) Evaluation of paper sludges for amenability to enzymatic hydrolysis and conversion to ethanol. Tappi J 84:50

Marques S, Santos JAL, Girio FM, Roseiro JC (2008) Lactic acid production from recycled paper sludge by simultaneous saccharification and fermentation. Biochem Eng J 41:210-216

Murashima K, Nishimura T, Nakamura Y, Koga J, Moriya T, Sumida N, Yaguchi T, Kono T (2002) Purification and characterization of new endo-1,4- $\beta$-Dglucanases from Rhizopus oryzae. Enzyme Microb Technol 30:319-326

Naresh KB, Zhiliang F (2009) Production of lactic acid from paper sludge usinf acid-tolerant, thermophilic Bacillus coagulan strains. Bioresour Tech 100:5966-5972

Nikolov T, Bakalova N, Petrova S, Benadova R, Spasov S, Kolev D (2000) An effective method for bioconversion of delignified waste cellulose fibers from the paper industry with a cellulase complex. Bioresour Technol $71: 1-4$

Passos FV, Fleming HP, Ollis DF, Felder RM, Mcfeeters RF (1994) Kinetics and modeling of lactic-acid production by Lactobacillus plantarum. Appl Environ Microbiol 60:2627-2636

Ping Huang L, Jin B, Lant P (2005) Direct fermentation of potato starch waste water to lactic acid by Rhizopus oryzae and Rhizopus arrhizus. Bioprocess Biosyst Eng 27:229-238

Skory CD, Freer SN, Bothast RJ (1998) Production of L-lactic acid by Rhizopus oryzae under oxygen limiting conditions. Biotechnol Lett 20:191-194

Sreenath HK, Moldes AB, Koegel RG, Straub RJ (2001) Lactic acid production by simultaneous saccharification and fermentation of alfalfa fiber. J Biosci Bioeng 92:518-523

Tanaka T, Hoshina M, Tanabe S, Sakai K, Ohtsubo S, Taniguchi M (2006) Production of D-lactic acid from defatted rice bran by simultaneous saccharification and fermentation. Bioresour Technol 97:211-217

Thongchul N, Yang S-T (2003) Controlling filamentous fungal morphology by immobilization on a rotating fibrous matrix to enhance oxygen transfer and L-(+)lactic acid production by Rhizopus oryzae. Ferment Biotechnol 3:36-51

Tripepi RR, Zhang X, Campbell AG (1996) Use of raw and composted paper sludge as a soil additive or mulch for cottonwood plants. Compost Sci Util 4:26-30

Wang L, Zhao B, Liu B, Yang C, Yu B, Li Q, Ma C, Xu P, Ma Y (2010) Efficient production of L-lactic acid from cassava powder by Lactobacillus rhamnosus. Bioresour Technol 101:7895-7901

Woiciechowski AL, Soccol CR, Romas LP, Pandey A (1999) Experimental design to enhance the production of $L-(+)$-lactic acid from steam-exploded wood hydrolysate using Rhizopus oryzae in a mixed-acid fermentation. Proc Biochem 34:949-955

Wyman CE (2003) Potential synergies and challenges in refining cellulosic biomass to fuels, chemicals, and power. Biotechnol prog 19:254-262 
Yanez R, Moldes AB, Alonso JL, Parajo JC (2003) Production of D-(-)-lactic acid from cellulose by simultaneous saccharification and fermentation using Lactobacillus coryniformis subsp. torquens. Biotechnol Lett 25:1161-1164 Yin P, Nishina N, Kosakai Y, Yahiro K, Park K, Okabe M (1997) Enhanced production of $\mathrm{L}(+)$-lactic acid from corn starch in a culture of Rhizopus oryzae using an air-lift bioreactor. J Ferment Bioeng 84:249-253
Zhou Y, Dominguez JM, Cao N, Du J, Tsao GT (1999) Optimization of L-lactic acid production from glucose by Rhizopus oryzae ATCC52311. Appl Biochem Biotechnol 77-79:401-407

\section{Submit your manuscript to a SpringerOpen ${ }^{\circ}$ journal and benefit from:}

- Convenient online submission

- Rigorous peer review

- Immediate publication on acceptance

- Open access: articles freely available online

- High visibility within the field

- Retaining the copyright to your article 